\title{
Auditory Lexical Decision
}

\author{
Stephen D. Goldinger \\ Arizona State University, Tempe, Arizona, USA
}

\begin{abstract}
Auditory lexical decision entails speeded classification of spoken words and nonwords. Given its implicit requirement of full lexical processing, auditory lexical decision has wide applicability. Indeed, the paradigm is currently used to study basic processes in word recognition, the nature of the mental lexicon, effects of word frequency, neighbour effects and various other phenomena of isolated word perception. In addition, auditory lexical decision is commonly used as a measure of priming and context effects, and as an index of impairments following brain damage. This summary reviews the strengths and weaknesses of the task, and provides citations to prominent articles.
\end{abstract}

\section{Issues Addressed}

1. Effects of numerous lexical variables on access time.

2. The nature of lexical representations (phonetic, phonological, morphological, and semantic/associative specifications).

3. Effects of lexical analogies on nonword rejection time.

4. Effects of semantic and form-based priming manipulations.

\section{First Uses}

1. Visual lexical decision: Rubenstein, Garfield and Millikan (1970).

2. Auditory lexical decision: McCusker, Holley-W ilcox and Hillinger (1979; cited in McCusker, Hillinger, \& Bias, 1981); Marslen-Wilson (1980).

Requests for reprints should be addressed to S.D. Goldinger, Department of Psychology, Box 871104, Arizona State University, Tempe, AZ 85287-1104, USA. E-mail: goldinger@asu.edu

This research was supported by NIDCD Grant No. R29-DC02629-02 to Arizona State University. Thanks to Ken Forster, Lorraine Tyler, Ludovic Ferrand and Jose Morais for comments on an earlier draft of the manuscript. 


\section{Description}

Spoken words and nonwords (usually equal numbers of each) are presented in random order to a listener for speeded classification. The stimuli may be presented in isolation or preceded by priming (or other contextual) stimuli. A variation of this method is a "go/no-go" procedure in which listeners are instructed to give a response when one type of stimulus (usually a nonword) is perceived, and to withhold the response when the other type of stimulus is perceived.

\section{Stimuli}

Spoken words and nonwords.

\section{Dependent variables}

1. Response latency (reaction time, RT) of correct word and nonword classifications.

2. Classification accuracy for words and nonwords.

3. Magnitudes of priming effects, relative to appropriate baselines.

4. Event-related potentials evoked during processing.

\section{Independent Variables}

1. Various lexical characteristics (length, frequency, spoken stress, neighbourhood characteristics, etc.).

2. Nonword characteristics (deviation point from real words, neighbourhood characteristics, magnitude of deviation from real words, etc.).

3. Contextual characteristics (semantic or form priming, etc.).

\section{Analysis Issues}

Reaction times measured from word onsets may be insensitive to various structural differences among stimulus items, especially if the uniqueness point is not properly controlled. For example, if one were interested in effects of word frequency, such effects may be either reduced (if lowfrequency words had earlier mean uniqueness points) or inflated (if the opposite confound existed). Goodman and Huttenlocher (1988) and Marslen-Wilson (1990) both discuss proper means of estimating RTs. In the interest of conservatism, it may be wisest to measure RTs using both onsets and uniqueness points as referents. Additionally, one must examine overall item durations to ensure that they are not confounded with manipulated 
variables. Returning to the example of word frequency, if the recorded tokens of low- and high-frequency words differed in mean durations by $100 \mathrm{msec}$ (such that high-frequency words were shorter), measuring RTs from word onset could inflate the observed frequency effect by $100 \mathrm{msec}$. When such variations exist, it may be advisable to include token durations as covariates in all analyses. Hopefully, most reliable effects will be reflected by all procedures.

\section{Effects Found with Paradigm}

\section{Word acceptance data}

1. Word frequency

Shown by: McCusker et al. (1979); Marslen-Wilson (1990); Slowiaczek and Pisoni (1986); Luce (1986); Taft and Hambly (1986).

2. Neighbourhood density and frequency (competitor effects)

Shown by: Luce (1986).

Not found by: Marslen-Wilson (1990).

3. Repetition priming Shown by: Slowiaczek and Pisoni (1986).

4a. Semantic priming

Shown by: Radeau (1983). Compared to visual semantic priming (using measures of event-related potentials, ERPs) by Holcomb and Neville (1990); Moss, Ostrin, Tyler and Marslen-Wilson (1995).

4b. Semantic priming with nonwords that phonetically resemble words Shown by: Milberg, Blumstein and Dworetzky (1988a) in normals; Milberg, Blumstein and Dworetzky (1988b) in Broca's aphasics.

5. Morphological priming

Shown by: Emmorey (1989); Kempley and Morton (1982); MarslenWilson, Tyler, Waksler and Older (1994); Marslen-Wilson and Zhou (submitted). See also Schreuder and Baayen (1995); Taft and Kinoshita (1986).

6. Syllable priming

Shown by: Corina (1992) with initial-syllable overlap; Emmorey (1989) with final-syllable overlap.

7a. Facilitatory phonological priming

Shown by: Slowiaczek and Hamburger (1992); Goldinger, Luce, Pisoni and Marcario (1992; Goldinger et al. attributed this effect to bias); Radeau, Morais and Segui (1995).

7b. No phonological priming

Shown by: Slowiaczek and Pisoni (1986); Marslen-Wilson et al. (1994). 
7c. Inhibitory phonological priming

Shown by: Slowiaczek and Hamburger (1992); Radeau, Morais and Dewier (1989); Goldinger et al. (1992); Radeau et al. (1995).

8. Inhibitory phonetic priming Shown by: Goldinger et al. (1992).

9. Priming by gender-marking (in French) Shown by: Grosjean et al. (1994).

10. Uniqueness point effect (faster responses to words with earlier uniqueness points)

Shown by: Taft and Hambly (1986); Marslen-Wilson (1990); Soares, Collet and Duclaux (1991).

11. Sensitivity to subtle phonetic anomalies

Shown by: Streeter and Nigro (1979); Whalen (1991); Andruski, Blumstein and Burton (1994). Evidence re-examined by MarslenWilson and Warren (1994).

12. Influence of expected versus unexpected lexical stress patterns Shown by: Slowiaczek (1990).

13. Influence of spelling of preceding spoken word Shown by: Jakimik, Cole and Rudnicky (1985).

\section{Nonword rejection data}

1. Neighbourhood density and frequency (competitor effects) Shown by: Luce (1986); Luce, Pisoni and Goldinger (1990).

2. Neighbourhood frequency Shown by: Luce (1986); Luce et al. (1990).

3. Uniqueness point effects Shown by: Marslen-Wilson (1980). Not found by: Goodman and Huttenlocher (1988).

4. Slowed by similarity to real words Shown by: Taft and Hambly (1986).

\section{Validity}

1. High replicability for some effects (e.g. word frequency) with mixed results for others (e.g. neighbourhood effects).

2. Replicability across subject populations, e.g. Broca's aphasics (Milberg et al., 1988b).

3. Generally strong agreement with auditory word naming (e.g. Luce et al., 1990), although effects are occasionally stronger in lexical decision. This 
may either implicate an excessive role of the decision stage in creating total RT (Balota \& Chumbley, 1984), or it may reflect relatively shallow/automatic processing in naming.

\section{Advantages}

1. Easy to use (although nonwords must be prepared).

2. Nonword rejection data provide elegant complement to word acceptance data.

3. Nonwords' amounts and temporal points of phonetic deviation from real words are easily manipulated.

4. Provides relatively "on-line" data.

5. Lexical decision blends easily with priming manipulations.

6. Stimuli can be presented without degradation via noise, etc., in contrast to tasks such as perceptual identification or gating.

7. Data can be analysed via signal-detection methods.

\section{Potential Artifacts}

1. The nature of the nonwords may "exaggerate" effects of lexical variables, primarily by increasing decision difficulty.

2. Response times must be measured in several convergent ways to ensure reliability. For example, uniqueness points (or "alignment points"; Marslen-Wilson, 1990) should be examined (see Analysis Issues).

3. In priming procedures, the roles of bias and "true priming" should be investigated (Goldinger et al., 1992).

\section{Problems}

1. Nonword RTs must be carefully examined, as mentioned in Potential Artifacts (point 2).

2. The role of the decision stage should be assessed. For example, word-frequency effects are typically inflated in lexical decision relative to naming. Both should be used in tandem to ensure that some proportion of an effect is due to perceptual processes.

3. Natural language processing rarely requires word/nonword distinctions. Although most laboratory tasks are artificial, issues of ecological validity should be considered before lexical decision data are treated as a veridical reflection on lexical access.

\section{Uses with Other Populations}

Auditory lexical decision is widely used in cross-population research.

1. Aphasics. Comparisons of Broca's and Wernicke's syndromes have suggested that only Wernicke's aphasics experience automatic lexical 
activation via priming (Blumstein et al., 1991; Milberg, Blumstein, \& Dworetzky, 1987; Milberg, Blumstein, Katz, \& Gershberg, 1995; Prather, Shapiro, Zurif, \& Swinney, 1991; Prather, Zurif, Stern, \& Rosen, 1992; also Milberg \& Blumstein, 1981, with visual LDT). However, these reports have been countered with positive priming effects in Broca's aphasics (Blumstein, Milberg, \& Shrier, 1982; Hagoort, 1993; Katz, 1988; Ostrin \& Tyler, 1993). Other lexical decision research on aphasia has examined processing of openand closed-class words (Gordon \& Caramazza, 1982; Matthei \& Kean, 1989).

2. Bilinguals. Shared or separate processes? (Woutersen, de Bot, \& Weltens, 1995, and references therein).

3. Children vs adults. Comparisons provided by Edwards and Lahey (1993) and Radeau (1983); see also Zecker and Zimmer (1987) for an examination of reading-disabled children.

\section{Other Comments}

1. One important issue is that differences may be observed between auditory and visual lexical decision data. For example, neighbourhood effects seem to be opposite across modalities (Goldinger, 1989) and different access representations may be entailed (Marslen-Wilson \& Zhou, submitted). Also, some manipulations (e.g. legal vs illegal nonwords) are not feasible in the auditory domain (see Bradley \& Forster, 1987, for a discussion). Naturally, generalising across modalities must be ventured cautiously.

2. Another heavily studied procedure is cross-modal priming, in which visual targets are presented for lexical decision while spoken words or nonwords are presented over headphones. This procedure is quite effective for examining cohort reduction processes, neighbourhood dynamics and other related issues. For information, see Connine, Blasko and Titone (1993), Marslen-Wilson (1990), Marslen-Wils on and Zwitserlood (1989) as well as the four priming summary sheets in this issue.

\section{References}

Andruski, J.E., Blumstein, S.E., \& Burton, M. (1994). The effect of subphonetic differences on lexical access. Cognition, 52, 163-187.

Balota, D.A., \& Chumbley, J.I. (1984). Are lexical decisions a good measure of lexical access? The rule of word frequency in the neglected decision stage. Journal of Experimental Psychology: Human Perception and Performance, 10, 340-357.

Blumstein, S.E., Milberg, W., \& Shrier, R. (1982). Semantic processing in aphasia: Evidence from an auditory lexical decision task. Brain and Language, 17, 301-315.

Blumstein, S.E., Milberg, W., Dworetzky, B., Rosen, A., \& Gershberg, F. (1991). Syntactic priming effects in aphasia: An investigation of local syntactic dependencies. Brain and Language, 40, 393-422.

Bradley, D.C., \& Forster, K.I. (1987). A reader's view of listening. Cognition, 25, 103-134. 
Connine, C.M., Blasko, D.G., \& Titone, D. (1993). Do the beginnings of words have a special status in auditory word recognition? Journal of Memory and Language, 32, 193-210.

Corina, D. (1982). Syllable priming and lexical representations: Evidence from experiments and simulations. In D.P. Corina (Ed.), Proceedings of the 14th Annual Conference of the Cognitive Science Society, pp. 779-784. Hillsdale, NJ: Lawrence Erlbaum Associates Inc.

Edwards, J., \& Lahey, M. (1993). Auditory lexical decision in children and adults: An examination of response factors. Journal of Speech and Hearing Research, 36, 996-1003.

Emmorey, K.D. (1989). Auditory morphological priming in the lexicon. Language and Cognitive Processes, 4, 73-92.

Goldinger, S.D. (1989). Neighbourhood density effects for high-frequency words: Evidence for activation-based models of word recognition. In Research on speech perception, progress report 15 . Bloomington, IN: Indiana University Press.

Goldinger, S.D., Luce, P.A., Pisoni, D.B., \& Marcario, J.K. (1992). Form-based priming in spoken word recognition: The roles of competition and bias. Journal of Experimental Psychology: Learning, Memory and Cognition, 18, 1210-1238.

Goodman, J.C., \& Huttenlocher, J. (1988). Do we know how people identify spoken words? Journal of Memory and Language, 27, 684-698.

Gordon, B., \& Caramazza, A. (1982). Lexical decision for open- and closed-class items: Failure to replicate differential frequency sensitivity. Brain and Language, 15, 143-160.

Grosjean, F., Dommergues, J., Cornu, E., Guillelmon, D., \& Besson, C. (1994). The gender-marking effect in spoken word recognition. Perception and Psychophysics, 56, 590-598.

Hagoort, P. (1993). Impairments of lexical-semantic processing in aphasia: Evidence of the processing of lexical ambiguities. Brain and Language, 45, 189-232.

Holcomb, P., \& Neville, H. (1990). Auditory and visual semantic priming in lexical decision: A comparison using event-related brain potentials. Language and Cognitive Processes, 5 , 281-312.

Jakimik, J., Cole, R.A., \& Rudnicky, A. (1985). Sound and spelling in spoken word recognition. Journal of Memory and Language, 24, 165-178.

Katz, W.F. (1988). An investigation of lexical ambiguity in Broca's aphasics using an auditory lexical priming technique. Neuropsychologia, 26, 747-752.

Kempley, M., \& Morton, J. (1982). The effects of priming with regularly and irregularly related words in auditory word recognition. British Journal of Psychology, 73, 441-454.

Luce, P.A. (1986). Neighborhoods of words in the mental lexicon. Doctoral dissertation, Indiana University, Bloomington, IN.

Luce, P.A., Pisoni, D.B., \& Goldinger, S.D. (1990). Similarity neighborhoods of spoken words. In G.T.M. Altmann (Ed.), Cognitive models of speech processing, pp. 122-147. Cambridge, MA: MIT Press.

Marslen-Wilson, W.D. (1980). Speech understanding as a psychological process. In J.C. Simon (Ed.), Spoken language understanding and generation, pp. 39-67. Dordrecht: Reidel.

Marslen-Wilson, W.D. (1990). Activation, competition, and frequency in lexical access. In G.T.M. Altmann (Ed.), Cognitive models of speech processing, pp. 148-172. Cambridge, MA: MIT Press.

Marslen-Wilson, W.D., \& Warren, P. (1994). Levels of perceptual representation and process in lexical access: Words, phonemes, and features. Psychological Review, 101, $653-675$.

Marslen-Wilson, W.D., \& Zhou, X. (submitted). Abstractness and the access of lexical form.

Marslen-Wilson, W.D., \& Zwitserlood, P. (1989). Accessing spoken words: The importance of word onsets. Journal of Experimental Psychology: Human Perception and Performance, 15, 576-585.

Marslen-Wilson, W.D., Tyler, L.K., Waksler, R., \& Older, L. (1994). Morphology and meaning in the English mental lexicon. Psychological Review, 101, 3-33. 
Matthei, E., \& Kean, M. (1989). Postaccess processes in the open- versus closed-class distinction. Brain and Language, 36, 163-180.

McCusker, L.X., Holley-Wilcox, P., \& Hillinger, M.L. (1979). Frequency effects in auditory and visual word recognition. Paper presented to the Southwestern Psychological Association (cited in McCusker et al., 1981).

McCusker, L.X., Hillinger, M.L., \& Bias, R.G. (1981). Phonological recoding and reading. Psychological Bulletin, 89, 217-245.

Milberg, W., \& Blumstein, S.E. (1981). Lexical decision and aphasia: Evidence for semantic processing. Brain and Language, 14, 371-385.

Milberg, W., Blumstein, S.E., \& Dworetzky, B. (1987). Processing of lexical ambiguities in aphasia. Brain and Language, 31, 138-150.

Milberg, W., Blumstein, S.E., \& Dworetzky, B. (1988a). Phonological factors in lexical access: Evidence from an auditory lexical decision task. Bulletin of the Psychonomic Society, 26, 305-308.

Milberg, W., Blumstein, S.E., \& Dworetzky, B. (1988b). Phonological processing and lexical access in aphasia. Brain and Language, 34, 279-293.

Milberg, W., Blumstein, S.E., Katz, D., \& Gershberg, F. (1995). Semantic facilitation in aphasia: Effects of time and expectancy. Journal of Cognitive Neuroscience, 7, 33-50.

Moss, H.M., Ostrin, R.K., Tyler, L.K., \& Marslen-Wilson, W.D. (1995). Accessing different types of lexical semantic information: Evidence from priming. Journal of Experimental Psychology: Learning, Memory and Cognition, 21, 863-883.

Ostrin, R.K., \& Tyler, L.K. (1993). Automatic access to lexical semantics in aphasia: Evidence from semantic and associative priming. Brain and Language, 45, 147-159.

Prather, P., Shapiro, L., Zurif, E., \& Swinney, D. (1991). Real-time examinations of lexical processing in aphasia. Journal of Psycholinguistic Research, 20, 271-281.

Prather, P., Zurif, E., Stern, C., \& Rosen, T. (1992). Slowed lexical access in nonfluent aphasia. Brain and Language, 45, 336-348.

Radeau, M. (1983). Semantic priming between spoken words in adults and children. Canadian Journal of Psychology, 4, 547-556.

Radeau, M., Morais, J., \& Dewier, A. (1989). Phonological priming in spoken word recognition: Task effects. Memory and Cognition, 17, 525-535.

Radeau, M., Morais, J., \& Segui, J. (1995). Phonological priming between monosyllabic spoken words. Journal of Experimental Psychology: Human Perception and Performance, $21,1297-1311$.

Rubenstein, H., Garfield, L., \& Millikan, J.A. (1970). Homographic entries in the internal lexicon. Journal of Verbal Learning and Verbal Behavior, 9, 487-494.

Schreuder, R., \& Baayen, H. (1995). Modeling morphological priming. In L.B. Feldman (Ed.), Morphological aspects of language processing, pp. 131-154. Hillsdale, NJ: Lawrence Erlbaum Associates Inc.

Slowiaczek, L.M. (1990). Effects of lexical stress in auditory word recognition. Language and Speech, 33, 47-68.

Slowiaczek, L.M., \& Hamburger, M. (1992). Prelexical facilitation and lexical interference in auditory word recognition. Journal of Experimental Psychology: Learning, Memory and Cognition, 18, 1239-1250.

Slowiaczek, L.M., \& Pisoni, D.B. (1986). Effects of phonological similarity on priming in auditory lexical decision. Memory and Cognition, 14, 230-237.

Soares, I., Collet, L., \& Duclaux, R. (1991). Electrophysiological correlates of auditory lexical decision: An attempt to test the "cohort model". International Journal of Neuroscience, 57, 111-122.

Streeter, L.A., \& Nigro, G.N. (1979). The role of medial consonant transitions in word perception. Journal of the Acoustical Society of America, 65, 1533-1541. 
Taft, M., \& Hambly, G. (1986). Exploring the cohort model of spoken word recognition. Cognition, 22, 259-282.

Taft, M., \& Kinoshita, S. (1986). Visual and auditory recognition of prefixed words. Quarterly Journal of Experimental Psychology: Human Experimental Psychology, 38, 351-365.

Whalen, D. (1991). Subcategorical phonetic mismatches and lexical access. Perception and Psychophysics, 50, 351-360.

Woutersen, M., de Bot, K., \& Weltens, B. (1995). The bilingual lexicon: Modality effects in processing. Journal of Psycholinguistic Research, 24, 289-298.

Zecker, S., \& Zimmer, T. (1987). Semantic code deficit for reading-disabled children in auditory lexical decision. Journal of Reading Behavior, 19, 177-190. 
